
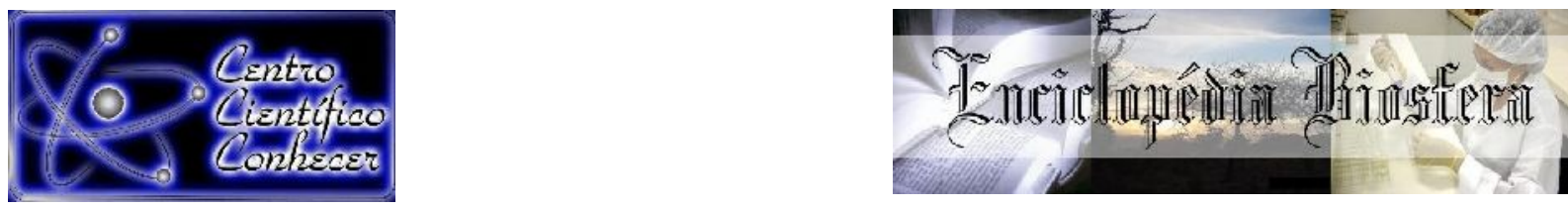

\title{
DETECÇÃO E ANÁLISE DE FOCOS DE CALOR NO MUNICÍPIO DE PARAUAPEBAS-PA, BRASIL POR MEIO DA APLICAÇÃO DE GEOTECNOLOGIA
}

Thiago Fernandes $^{1}$; Sandra de Souza Hacon²; Jonathan Willian Zangeski Novais ${ }^{3}$, Isaac Pereira de Sousa ${ }^{4}$; Thaiany Fernandes ${ }^{5}$

1Doutorando no Programa de Pós-Graduação Stricto Sensu em Ciências Ambientais da UNEMAT - Universidade do Estado de Mato Grosso; Cáceres, MT E-mail: thiago.ufra.pa@gmail.com

2Professora Doutora no Programa de Pós-Graduação Stricto Sensu em Ciências Ambientais da UNEMAT - Universidade do Estado de Mato Grosso; Cáceres, MT 3Professor Doutor no Programa de Pós-Graduação Stricto Sensu em Ciências

Ambientais da UNIC - Universidade de Cuiabá; Cuiabá, MT

${ }^{4}$ Graduando do Curso de Bacharelado em Engenharia de Produção - Universidade

Federal Rural da Amazônia - UFRA, Parauapebas, PA

${ }^{5}$ Graduanda do Curso de Bacharelado em Agronomia - Universidade do Estado de Mato Grosso - UNEMAT, Tangará da Serra, MT

Recebido em: 22/09/2018 - Aprovado em: 23/11/2018 - Publicado em: 03/12/2018 DOI: 10.18677/EnciBio_2018B34

\section{RESUMO}

As queimadas e os incêndios florestais figuram-se entre os principais problemas que agravam a existência da biodiversidade na Amazônia brasileira, o que tem origem num processo histórico complexo de utilização não adequada de seus recursos naturais. Neste estudo teve-se como objetivo analisar a distribuição e quantificação de focos de calor no município de Parauapebas-PA, por meio da aplicação de geotecnologias. Para isso, foram utilizados dados de focos de calor do Instituto Nacional de Pesquisa Espacial (INPE) e de precipitação, temperatura e umidade do ar do Instituto Nacional de Meteorologia (INMET). Como resultados, foram identificados, na série temporal de 6 anos, um total de 553 registros de focos de calor e, dentro desse quantitativo, o ano de 2015 registrou a maior quantidade, cerca de 143 focos, representando aproximadamente $25,86 \%$ desse total. Pela análise de Kernel, foi evidenciada uma maior concentração de densidade de focos de calor localizados próximos aos centros urbanos, região central e nordeste do município. Outrossim, a localização geográfica das áreas estudadas é um fator agravante no número de focos de calor, visto que representa uma região com intensas atividades de modificação no uso e ocupação do solo, principalmente com a chegada dos processos industrializados da cadeia produtiva da mineração. Portanto, pode-se concluir que a aplicabilidade de ferramentas de geotecnologias torna-se importante para a análise de focos de calor distribuídos em determinadas áreas, extremamente útil para o combate de queimadas irregulares no município de Parauapebas-PA.

PALAVRAS-CHAVE: Monitoramento; Distribuição, Focos de calor. 


\title{
DETECTION AND ANALYSIS OF SOURCES OF HEAT IN THE MUNICIPALITY OF PARAUAPEBAS-PA, BRAZIL THROUGH THE APPLICATION OF GEOTECHNOLOGY
}

\begin{abstract}
Burning and forest fires are included among the main problems that aggravate the existence of biodiversity in the brazilian Amazon, which has its origins in a complex historical process of proper use of its natural resources. This study had as objective to analyze the distribution and quantification of hotspots in the municipality of Parauapebas-PA, through the application of Geotechnology. For this, we used data from outbreaks of heat from the National Institute of Space Research (INPE) and precipitation, temperature and air humidity of the National Institute of meteorology (INMET). As a result, were identified in temporal series of 6 years, a total of 553 records for hotspots and, within that amount, the year 2015 recorded the largest amount, about 143 foci, representing approximately $25,86 \%$ of this total. Kernel analysis was evidenced a greater concentration of density of hotspots located near urban centres, central and northeast of the city. In addition, the geographic location of the studied areas is an aggravating factor in the number of hotspots, because that represents a region with intense activities of change in soil use and occupation, especially with the arrival of industrial processes mining production chain. Therefore, we can conclude that the applicability of geotechnologies tools becomes important for the analysis of heat distributed in certain areas, extremely useful for fighting irregular fire in the municipality of Parauapebas-PA.
\end{abstract}

KEYWORDS: Monitoring; Distribution, Sources of heat.

\section{INTRODUÇÃO}

O uso do fogo como uma técnica de preparo dos terrenos visando a agricultura é atribuído equivocadamente aos povos tribais de floresta (LEONEL, 2000). Dentre as atividades antropogênicas, as queimadas são as principais responsáveis pela liberação de partículas de aerossóis para o ar e essas partículas interagem com a radiação solar afetando o balanço de energia, bem como alterando o ciclo hidrológico local (NOVAIS et al., 2017).

Na Amazônia, há fogo por meio de ação humana e também de combustão espontânea que ocorre nos períodos de pouca precipitação, incluindo sinais de fogo e carvão que datam de milhares de anos (HECHT, 1989), a exemplo dos estudos feitos por Moran (1990), que comprovaram causas naturais para queimadas na região do rio Negro. Para Thomaz et al. (2014) seu uso pode levar a alterações nas propriedades físicas, químicas e biológicas abaixo da superfície do solo.

Segundo Araújo et al. (2013) essa prática mesmo que empregada de forma controlada causa vários danos ao meio ambiente como a perda da biodiversidade e a redução da biomassa na superfície, aumentando a susceptibilidade à erosão do solo (HUBBERT et al., 2006). Fearnside (2002) cita que outro dano proveniente do fogo na Amazônia brasileira é a emissão de grandes quantidades de gases de efeito estufa, sendo por meio da queimada de floresta nas áreas que estão sendo desmatadas para agricultura e pecuária, incêndios florestais e queimada de capoeiras, pastagens, e diferentes tipos de savanas. 
No Estado do Pará, um dos municípios da região sudeste que expõe altos índices de focos de calor devido a incêndios conexos à alteração do uso da terra, é Parauapebas, o qual teve seu surgimento ligado as políticas públicas nacionais da década de 70, com a motricidade da exploração de minerais entorno a região da Serra de Carajás (BARREIROS et al., 2017). Segundo o IBGE (2018), nos últimos dois sensos demográficos, o município apresentou aumento de $115 \%$ no seu crescimento populacional, saindo de 70.568 em 2000 para 153.908 habitantes, em 2010. Esse crescimento exorbitante aconteceu em virtude da migração de povos da região norte, nordeste e sudeste, com o início das obras de infraestruturas e investimentos relacionados ao projeto Ferro Carajás S11D, considerado o maior completo de mineração do mundo, sendo também a atividade mineral principal fonte de renda econômica e emprego na região. Além disso, existe relevância das atividades de garimpos e madeireiras, sendo essas responsáveis pela maioria de focos de incêndios.

Para Tomzhinski et al. (2011) existem diversas formas de detectar incêndios, como vigilância terrestre, posto de observação ou monitoramento por imagens de satélites. Embora, para países com grande extensão territorial como é o caso do Brasil, a técnica de sensoriamento torna-se mais rápido e com um custo menor, sendo de total eficiência para viabilizar o controle dos focos, os quais podem atentar grandes incêndios florestais.

Pereira et al. (2016) afirmam que as geotecnologias surgem como um importante recurso de subsídio na identificação das queimadas permitindo localizar, quantificar e fazer estudos de análises espaco-temporais das áreas onde ocorrem incêndios. Para Gomes (2006) enfatiza que uma ferramenta importante para essa identificação é o Sensoriamento Remoto que permite cruzar informações georeferenciadas e saber a quantidade e a localização desses focos. Segundo Lazzarini et al. (2016) focos de calor se caracterizam por serem pontos geográficos captados por sensores espaciais na superfície da terra, quando detectados a uma temperatura acima de $47^{\circ} \mathrm{C}$ em uma área mínima de $900 \mathrm{~m}^{2}$.

Assim, com o intuito de trazer uma contribuição científica para se estabelecer uma política adequada de prevenção de queimadas, visando a minimização dos impactos causados ao ambiente, através desta pesquisa, teve-se como objetivo foi detectar e analisar a distribuição e a quantificação de focos de calor no município de Parauapebas-PA, no período de 2011 a 2016, a partir de dados obtidos por monitoramento de satélite de referência.

\section{MATERIAL E MÉTODOS}

\section{Caracterização da área de estudo}

Este trabalho teve como área de estudo o município de Parauapebas-PA (Figura 1), localizado na região sudeste paraense, sob coordenadas geográficas Latitude 49은 54' 08" Sul e Longitude 06 04' 03" Oeste (IBGE, 2018). A seleção da área de estudo levou em consideração os relatórios produzidos pela Fundação Amazônia Paraense de Amparo à Pesquisa (2017), que identificou no Sudeste do Pará, regiões com densidade considerável de focos de calor sobrepostos às áreas urbanas e rurais em períodos quentes-secos. 


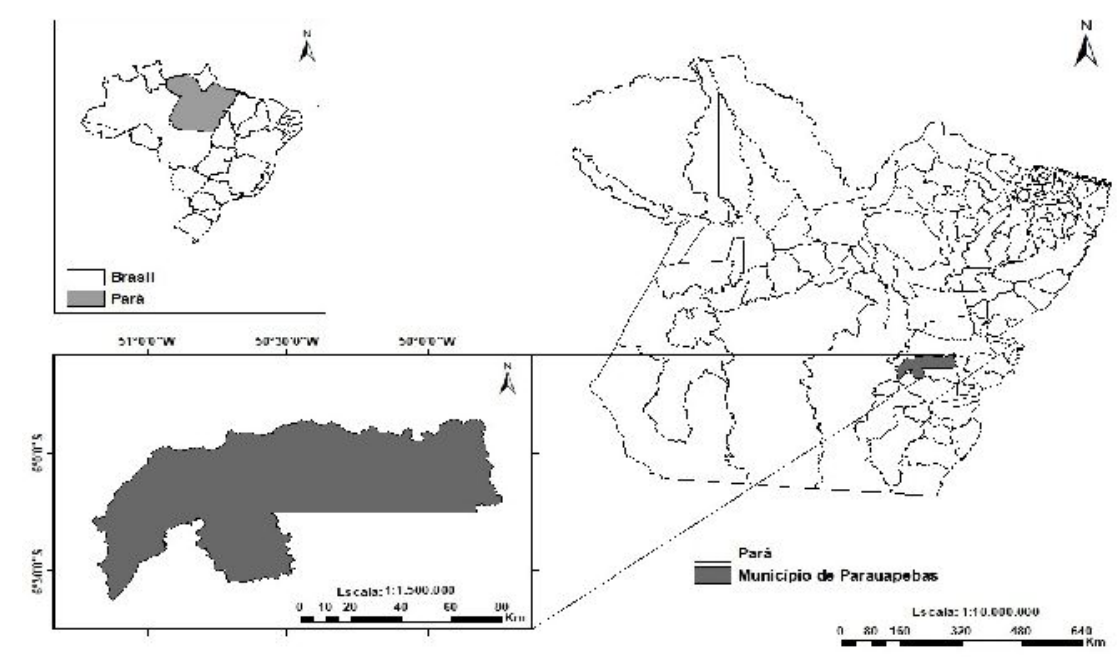

FIGURA 1 - Localização geográfica do município de Parauapebas-PA, Brasil.

Segundo Köppen, o clima predominante no município é classificado como Aw. Estimado como um clima tropical chuvoso (quente-úmido), possui duas estações climáticas bem definidas (verão chuvoso e inverno seco), caracterizando-se com temperatura média anual do ar de $26^{\circ} \mathrm{C}$, com máxima em torno de $32^{\circ} \mathrm{C}$ e mínima de $22^{\circ} \mathrm{C}$ (SETUR, 2012). A umidade relativa do ar é elevada, expondo oscilações entre a estação mais chuvosa e a mais seca, com máxima média anual de $78 \%$ e mínima de $32 \%$, respectivamente. O período chuvoso ocorre, notadamente, de novembro a maio, o mais seco, de junho a outubro, com precipitação média do mês mais seco inferior a $60 \mathrm{~mm}$ e média do mês mais chuvoso acima de $2.100 \mathrm{~mm}$ (AYOADE, 2003).

\section{Procedimentos metodológicos e interpretações estatísticas}

Os dados utilizados são procedentes do BDMEP - Banco de Dados Meteorológicos para Ensino e Pesquisa, Instituto Nacional de Meteorologia e do Bdqueimadas, Banco de Dados de Queimadas do Centro de Previsões de Tempo e Estudos Climáticos - CPTEC, disponível no site do Instituto Nacional de Pesquisas Espaciais (INPE), este em formato shapefile. Os dados meteorológicos de precipitação pluviométrica, temperatura e umidade relativa do ar foram obtidos a partir do processamento mensal da estação climática de referência (INMET, 2016) localizada na cidade de Parauapebas-PA (4949' W e 0604' S). Os dados de focos de calor foram obtidos a partir do processamento diário das imagens termais do sensor MODIS (Moderate Resolution Imaging Spectrodiometer) que está acoplado ao satélite AQUA_M-T, que é o atual satélite de referência do INPE, cuja os dados correspondem às informações geradas no período da manhã (passagem das 4h GMT) e da tarde (passagem das 17h GMT), permitindo a análise de tendências nos números de focos para as mesmas regiões (INPE, 2017).

A tabulação dos dados adquiridos, os shapefiles de focos de calor (2011 a 2016) foram sobrepostos à área de estudo, dispostos em uma única base de dados, para facilitar sua manipulação e iniciar o procedimento de interpretação das informações e geração de dados procedidos (anos e meses) dos focos de calor. Todo o processamento de dados foi realizado no software ArcGis, versão 10. Logo, após a 
sobreposição dos dados dos focos de calor e limites territoriais, dados matriciais de densidade de focos de calor acumulado para o período de estudo foram determinados por meio do algoritmo estimador de densidade de Kernel.

As densidades de Kernel foram distribuídas em 5 classes: muito baixa, baixa, média, alta e muito alta, seguindo o modelo de legenda aplicado por Lopes et al. (2017) em estudo de monitoramento de focos de calor de 2010 e 2015, para a cidade de Novo Progresso-PA e Oliveira et al. (2017) que analisaram a densidade de pontos de incêndio localizados na bacia hidrográfica do rio Acaraú, nos anos de 2010 a 2015, utilizando o estimador de densidade de Kernel. Assim, optou-se pela utilização do algoritmo estimador de densidade de Kernel por esse ser um indicador de fácil uso e explanação.

\section{RESULTADOS E DISCUSSÃO}

Conforme os dados coletados, na fase temporal de 6 anos, foram detectados por meio do satélite AQUA_M-T, um total de 553 focos de calor. No quantitativo anual, as ocorrências de focos de calor registradas foi maior em 2015, com 143 registros, seguido dos anos de 2014 e 2012, com 138 e 110 ocorrências. Desse modo, do total registrado de focos de calor durante os anos analisados, o ano de 2015 representou cerca de $25,86 \%$ dos focos, em seguida, o ano de 2014 com 24,95\% e 2012 com 19,90\%, respectivamente.

Lopes et al. (2017), analisando a distribuição de focos de calor entre os anos de 2010 a 2015, no municipio de Novo Progresso, localizado na mesorregião Sudoeste paraense, cerca de $1.630 \mathrm{~km}$ da capital Belém-PA, cerca de $718 \mathrm{~km}$ de distancia de Parauapebas-PA, concluíram que os anos de 2010, 2014 e 2015 corresponderam cerca de $71,86 \%$ do total de focos de calor, enquanto que os anos de 2011, 2012 e 2013 representaram índices de focos de calor considerados inferiores a taxa de estimativa padrão. Segundo Barreiros et al. (2017) realizando estudo sobre focos de calor no município de Parauapebas-PA na série tempora de 2005 a 2015, concluiram que os anos de 2005, 2007, 2012 e 2014 foram os que expuseram maior concentração de focos de calor, uma vez que as concentrações estão diretamente relacionadas as distâncias das rodovias, sendo que no período de 2005 a 2007 foi diagnosticado aumento no crescimento populacional, certamente, ocorrido pelo povoamento aglomerado, formação de bairros e, principalmente, abertura de estradas e rodoviarias para o escoamento de minérios e insumos.

Para o presente estudo, o total registrado durante os anos de 2012, 2014 e 2015 correspondeu a cerca $70,71 \%$ do total de focos de calor, enquanto que os anos de 2011, 2013 e 2016 exibiram um indicador de focos muito inferior, evidenciando que a distribuição anual total dos focos de calor (Figura 2) não possui um padrão de distribuição ao longo dos anos analisados. 


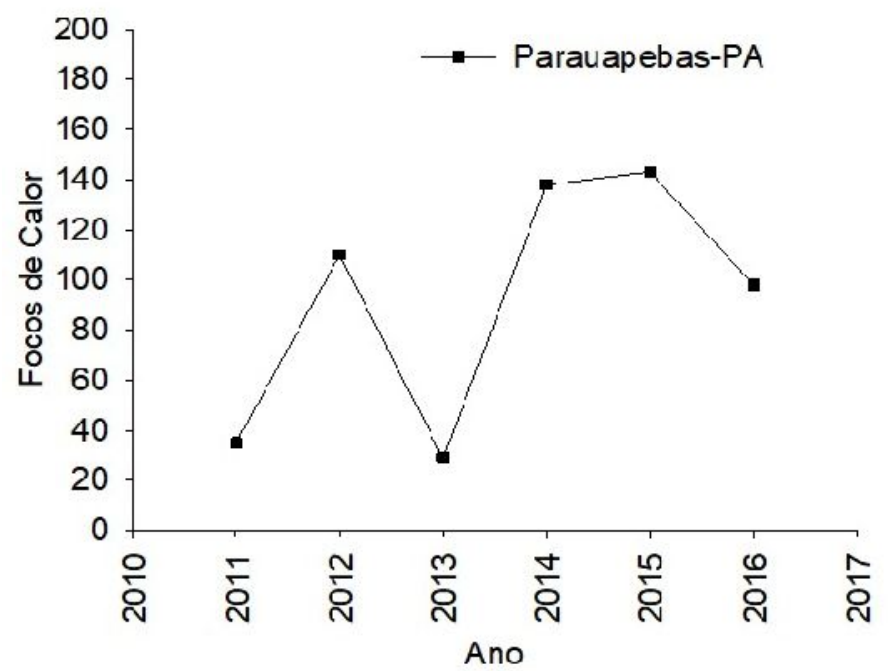

FIGURA 2 - Evolução dos focos de calor durante os anos de monitoramento no município de Parauapebas-PA, Brasil.

Em relação a distribuição mensal dos focos de calor, verificou-se que os meses de agosto, setembro e outubro se revelaram com os maiores valores, cerca de 460 ocorrências de focos de calor registrados pelo senso do satélite de referência AQUA_MT. Esse quantitativo representou cerca de $81,2 \%$ do total de focos de calor registrados mensalmente em todos os anos de estudo.

Anderson et al. (2017) realizando uma análise espaço-temporal do uso do fogo no Estado do Acre, a partir da utilização de dados orbitais, concluíram que para a série temporal estudada entre os anos de 2001 a 2015, os meses de julho a outubro representaram mais de $97 \%$ dos totais anuais de focos de calor. O valor mínimo observado foi em 2011, em que o quadrimestre contou com $93 \%$ das observações dos focos de calor. Neste mesmo período, observou-se também um número maior de detecções em junho e principalmente em novembro. Por outro lado, nos anos de 2001, 2003 e 2005, mais de $99 \%$ dos focos de calor foram observados entre julho e outubro. Agosto e setembro foram o bimestre principal de ocorrência de queimadas e incêndios, variando de $80 \%$ (em 2001) a 90\% (em 2005) das detecções, exceto em 2002, 2008 e 2009. Com exceção do ano de 2001, o mês de pico para as observações de focos de calor foi setembro.

Na região Norte brasileira, já se observa a prevalência de períodos de seca no Leste da Amazônia e de chuvas intensas no Oeste da Amazônia (HUGHES; SAUNDERS, 2002). Neste atual cenário, a região de estudo vem demonstrando frequências sucessivas de estiagens mais intensa (Figura 3), levando a ocorrência de incêndios florestais e agravando as condições para produção agrícola e qualidade de vida. 


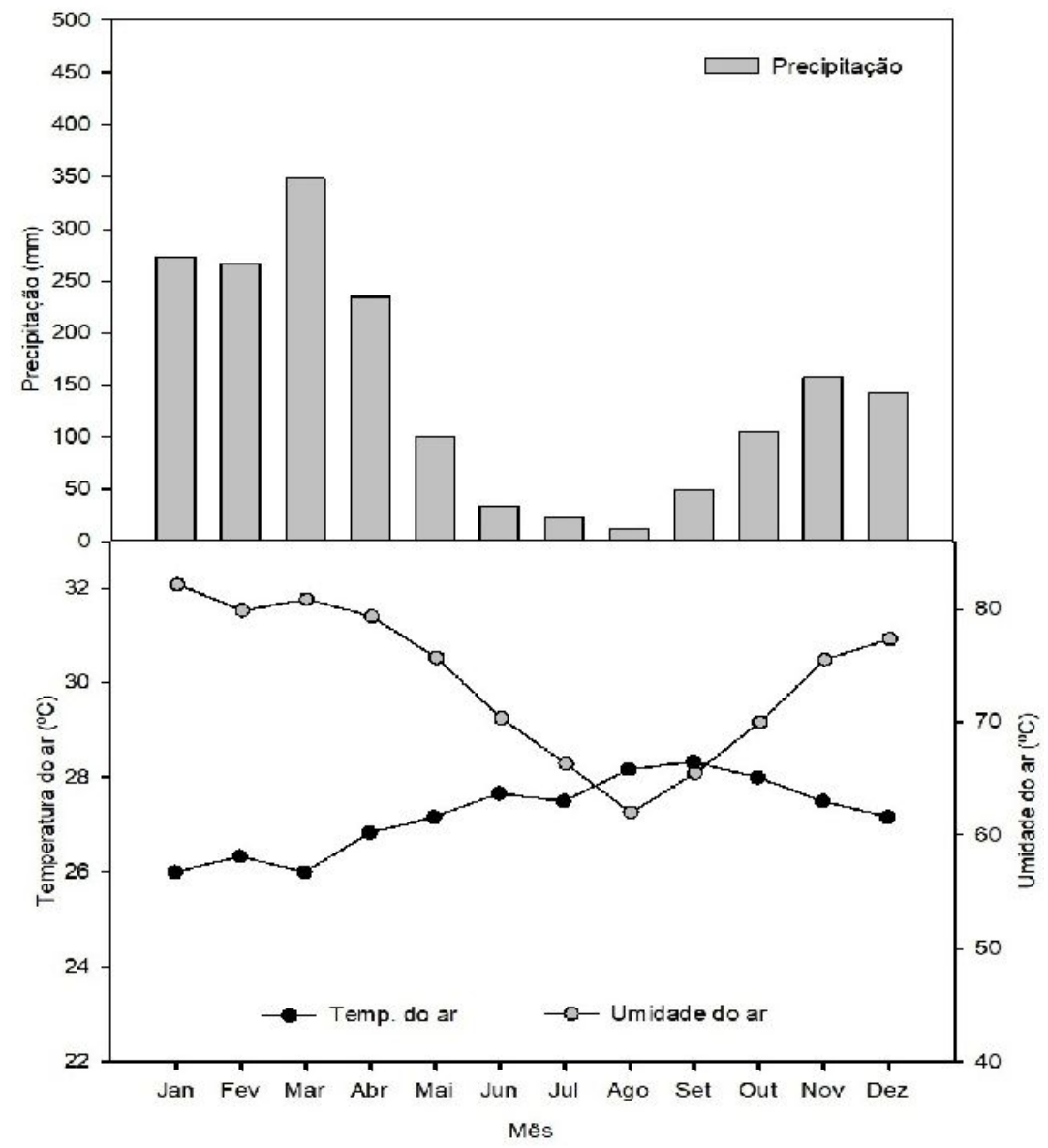

FIGURA 3 - Médias mensais de precipitação pluviometrica $(\mathrm{mm})$, temperatura do ar $\left({ }^{\circ} \mathrm{C}\right)$ e umidade relativa do ar (\%) do municipio da Parauapebas-PA, para os anos de 2011 a 2016.

Para o período analisado, com base nos dados de precipitação, é possível caracterizar que a região apresenta duas estações climáticas, uma chuvosa e outra seca. Para Vieira et al. (2010) a estação de seca corresponde aos meses de menor precipitação, sendo de maio a outubro, enquanto que os demais meses (de novembro a abril) caracterizam como estação chuvosa, devido exporem maiores volumes de chuvas. No estudo, para a estação seca, houve um aumento da temperatura do ar nos meses de maio a outubro e no mesmo período, de forma inversa, a umidade relativa do ar teve uma queda em relação ao período chuvoso, expondo temperatura média mensal de mínima de $26^{\circ} \mathrm{C}$ e máxima de $28,3^{\circ} \mathrm{C}$, umidade média mensal mínima de $62 \%$ e máxima de $82,2 \%$.

Em análise dos dados de precipitação acumulada, destaca-se o ano de 2011 como o mais chuvoso, chegando a 2172,3 mm, e o de 2012 com a maior predominância de estiagem, com 1398,7 mm. Em 2012, no entanto, a média anual da temperatura do ar foi a menor entre os 6 anos, sendo de $26,92^{\circ} \mathrm{C}$, enquanto que a maior amplitude térmica correspondeu ao ano de 2016 , com $27,67^{\circ} \mathrm{C}$. Também em 2012, a umidade relativa média anual do ar foi a menor, com $71,25 \%$, e o ano de 2013 , 
representou a maior umidade relativa média anual, sendo esse de 75,67\%, respetivamente.

Diante da relação existente nos mapas de densidade de Kernel (Figura 4), produto da interpolação dos focos de calor, conforme os anos de estudos, ressalva-se sua magnitude na área estudada, aferindo-se assim a sua densidade por meio das cinco classes estimadas, sendo: muito baixa, baixa, média, alta e muito alta.
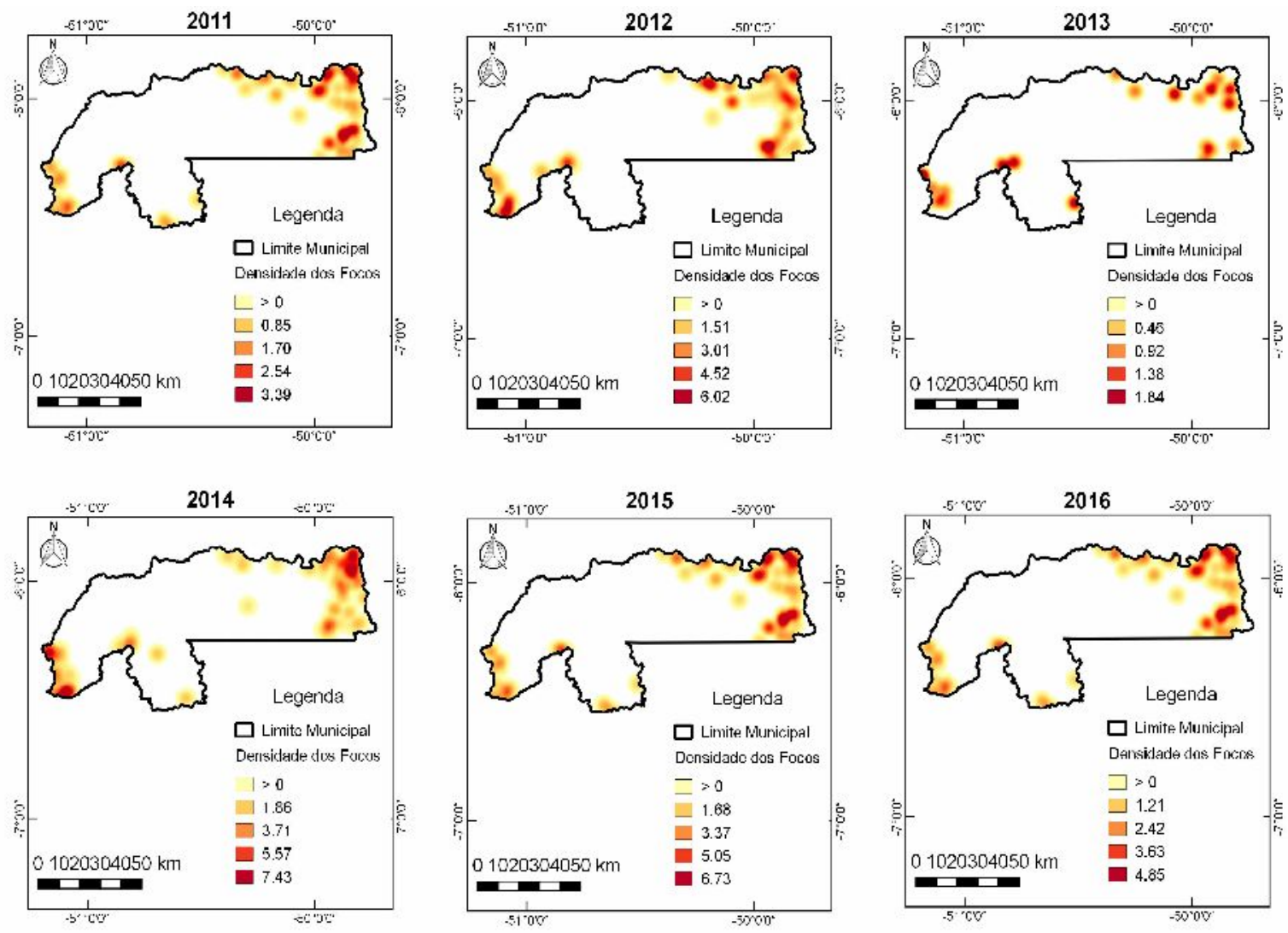

FIGURA 4 - Mapas de densidade dos focos de calor detectados pelos sensores do satélite AQUA_M-T para os anos de 2011 a 2016 em Parauapebas-PA, Brasil.

Nos mapas de Kernel (Figura 4) referentes aos resultados da interpolação dos focos de calor ao longo de cada ano para Parauapebas-PA, observou-se que a região nordeste concentra-se a maior distribuição da densidade de focos. Na análise, os anos de 2012, 2014 e 2015 foram os que evidenciaram as maiores densidades de focos de calor, em escala alto e muito alta, com prevalência de extensão de manchas na região nordeste perimetral, especificamente na área em que foi construído o núcleo urbano de Carajás, em função das primeiras ocupações e povoamento por migrantes a trabalho na Companhia Vale do Rio Doce - CVRD e terceirizadas.

Segundo informações disponíveis pelo projeto PRODES, do Instituto Nacional de Pesquisas Espaciais (INPE, 2011), que sistematiza sobre desmatamento nos municípios da Amazônia, a cidade de Parauapebas-PA constatou no ano de 2000 um desflorestamento de 16\%, e em 2005 com 18\%, sobretudo com uma taxa média anual de desmatamento de $2 \%$ de 2000/2005. A grosso modo, Araújo et al. (2013) citam que 
essa taxa sobrepõe a do Estado do Pará, que apresentou um desflorestamento de $12 \%$ em 2000 e de 17\% em 2005, com uma taxa média anual de 6\%, embora, a variação é mais expressiva em municípios considerados de base mineral.

$\mathrm{Na}$ mesma vertente de pensamento, Enríquez (2007) pesquisando sobre os dilemas do desenvolvimento sustentável a partir de uma base mineira, cita que no ano de 1970, o município de Oriximiná localizado na mesorregião do Baixo Amazonas, foi o primeiro município paraense a abrigar um empreendimento mineral de larga escala de produção para o mercado internacional. Contudo, tanto esse como outros municípios ao seu redor contextualizaram as mais altas taxas de desmatamento do estado.

Desta forma, uma explicação mais sensata sobre o nível de densidade observados nesses anos pode ser devido ao uso e ocupação de terras para construção de residenciais, desapropriações e desmatamento para construção de estradas e rodovias, ocupação irregular de áreas frágeis, aterro das margens do rio, queimadas, desmatamento da vegetação ciliar para construção de projetos de empreendimentos comerciais, bem como construção das linhas e ramais ferroviários, que hoje ligam a cidade de Parauapebas-PA a São Luiz-MA, sustentando a produção e a logística de minérios até os portos.

Nesse contexto, Parauapebas-PA é um dos municípios brasileiros que sobrevive com economia baseada no segmento minerário, em que a abundância de recursos naturais, como o minério de ferro, tem colocado o Estado do Pará em posição de destaque. Segundo a Agência Nacional de Mineração (2018), o Estado do Pará representa mais de $60 \%$ da produção de minérios no Brasil, assegurando no ranking, sete empresas das vinte e cinco maiores produtoras desta matéria-prima, permanecendo o município de Parauapebas-PA em primeira colocação, (MONTEIRO, 2005) a título como o maior em potencial de geração econômica a partir de operações minerais.

A maioria dessas manchas corresponde as áreas ocupadas próximas da passagem da rodovia PA 279 e 275, pois tendem a ser valorizadas por reduzirem os passivos de transportes e de produção. A partir do ano de 2014, observou-se manchas de densidade na concentração média, com maior proporção de focos no entorno dos limites perimétricos do município, circunvizinho a Água Azul do Norte, Canaã dos Carajás e Curionópolis.

Subsequente, ao analisar os anos de 2011 e 2013, observou-se redução nas densidades de focos de calor na classe baixa, distribuídas nas regiões sul, sudeste e noroeste do município. Novamente Lopes et al. (2017) que também analisaram focos de calor pela técnica de estimação de Kernel no município de Novo Progresso-PA, comprovaram que no ano de 2015 houve prevalência de manchas de densidades dispersas na região nordeste da sede do município que, resultaram em densidade alta e muito alta, justamente sobreposta a ocupação de terras que, atualmente, é constituído por um assentamento da reforma agrária. Outro importante entrave nesse mecanismo de expansão é o desflorestamento acumulado (Tabela 1), que é sinérgico a essas atividades primárias.

TABELA 1 - Quantitativo do desflorestamento acumulado $\left(\mathrm{km}^{2}\right)$ e focos de calor em 2016. 


\begin{tabular}{c|c|c}
\hline Municípios/UF & $\begin{array}{c}\text { Desflorestamento } \\
\left.\text { Acumulado } \mathbf{( k m}^{2}\right)\end{array}$ & $\begin{array}{c}\text { No de focos de } \\
\text { Calor }\end{array}$ \\
\hline Pará-PA & 262.037 & 29.316 \\
\hline Parauapebas-PA & 1.323 & 98 \\
\hline
\end{tabular}

$\mathrm{Na}$ tabela acima, percebe-se que em 2016 o município de Parauapebas-PA destacou-se devido as atividades antrópicas, com $1.651 \mathrm{~km}^{2}$ desflorestado, o que representou $0,5 \%$ em relação ao desmatamento ocorrido em todo o Estado. No mesmo ano, foram registrados 98 focos de calor, representando $0,33 \%$ comparado ao total de focos registrado em todo o Estado do Pará-PA.

Observou-se também que nesse ano, o município de Parauapebas-PA não demonstrou densidades expressivas de focos de calor na região norte e noroeste do perímetro municipal, muito provável devido ao fato de serem áreas de exploração contínua de minérios pela CVRD, e estando essas áreas preservadas pelas suas políticas ambientais, evitando a migração e/ou qualquer outro desenvolvimento de atividades produtivas.

Segundo Silva e Bacha (2014) e Abreu e Souza (2016), a ocupação urbana provoca uma força motriz e pressão no solo, gerando zonas urbanas intrarregionais, resultante da concentração da população aglomerada. Os resultados obtidos de densidade de focos de calor podem ser analisados na Figura 5, que expõe sua variação anual por valores e classes.

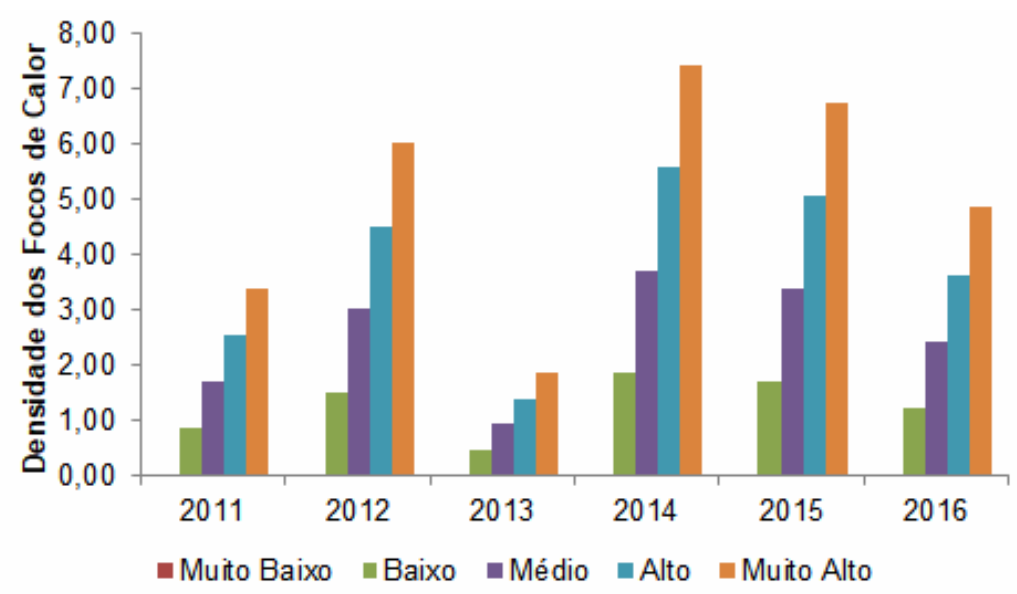

FIGURA 5 - Variação anual das classes de densidade dos focos de calor detectados pelos sensores do satélite AQUA_M-T para os anos de 2011 a 2016, no município de Parauapebas-PA.

Analisando os anos de 2011 e 2012, verificou-se um aumento de densidade de focos de calor em todas as classes. Entretanto, no ano de 2013, foi susceptível uma redução dos focos de calor, o que reforça a afirmação observada de que as manchas de densidade alta e muito alta reduziram consideravelmente. Conseguinte, nos anos de 2014 à 2016, a densidade anual de focos de calor se manteve equilibrada, reforçando a mesma afirmativa discutida anteriormente, em que as manchas de densidade alta e 
muita alta se intensificam em locais próximos aos centros urbanos e entorno da passagem das rodovias que cortam o município, (FURTADO et al. 2014) ocupadas pela proliferação da grande migração atraídos pelo Projeto Grande Carajás - PGC, entre as décadas de 70 e 80.

Um estudo desenvolvido por Costa et al. (2017), relacionando o monitoramento das alterações no uso e ocupação da terra e focos de calor, especificamente, as modificações no uso da terra na área de influência da rodovia BR-163, no trecho Cuiabá-Santarém, apresentaram resultados que reforçaram a afirmação de que, mudanças na cobertura vegetal primária estão relacionadas à agricultura e pecuária, usando a queimada, para a limpeza da área.

\section{CONCLUSÃO}

O município de Parauapebas-PA registrou no período de 2011-2016 um total de 553 focos de queimadas. No quantitativo anual, em 2015 houve a maior quatidade de focos, com 143 registros, seguido dos anos de 2014 e 2012, com 138 e 110 ocorrências, sendo que, do total registrado durante os anos analisados, 2015 representou cerca de 25,86\% dos focos e em seguida, o ano de $2014 \mathrm{com} 24,95 \%$ e 2012 com 19,90\%.

A análise do regime pluviométrico feita para a região contribuiu para corroborar com a afirmativa da existência de duas estações climáticas definidas, uma de novembro a abril (quente-úmida) e a outra de maio a outubro (quente-seca). Em todos os anos analisados, houve prevalência de aumento de focos de calor em período de estiagem, com alta intensidade de focos nos meses de julho, agosto e setembro. Através do estimador de densidade kernel foi possível a análise do comportamento dos focos de calor, gerando-se informações qualitativas acerca do município de Parauapebas-PA, no período estudado.

Por fim, concluiu-se que a aplicabilidade de ferramentas de geotecnologias tornase importante para a análise de focos de calor distribuídos em determinadas áreas. Assim, sua empregabilidade auxilia na quantificação e no monitoramento dos focos no espaço e no tempo.

\section{REFERÊNCIAS}

ABREU, F. A.; SOUZA, J. S. A. Dinâmica espaço-temporal de focos de calor em duas terras indígenas do estado de Mato Grosso: uma abordagem geoespacial sobre a dinâmica do uso do fogo por xavantes e bororos. Floresta e Ambiente, v. 23, n. 1, p. 110, 2016. Disponível em: http://www.scielo.br/pdf/floram/v23n1/2179-8087-floram-21798087041813.pdf Acesso em: 01 de ago. 2018.

ANDERSON, L. O., YAMAMOTO, M., CUNNINGHAM, C., FONSECA, M. G., FERNANDES, L. K., PIMENTEL, A. \& SALAZAR, N. Utilização de dados orbitais de focos de calor para caracterização de riscos de incêndios florestais e priorização de áreas para a tomada de decisão. Revista Brasileira de Cartografia, v. 69, n. 1, 2017. Disponível em: http://www.seer.ufu.br/index.php/revistabrasileiracartografia/article/view/44038/23289 Acesso em: 02 de jul. 2018. 
ANM - Agencia Nacional de Mineração. Novos rumos para o setor, 2018. Disponível em:

http://www.revistamt.com.br/index.php?option=com_conteudo\&task=printMateria\&id=30 31 Acesso em: 20 de fev. 2018.

ARAÚJO, J. B.; OLIVEIRA, L. C.; VASCONCELOS, S.S.; CORREIA, M.F. Danos provocados pelo fogo sobre a vegetação natural em uma floresta primária no estado do Acre, Amazônia Brasileira. Ciência Florestal, Santa Maria, v. 23, n. 2, p. 297-308, 2013. Disponível em: http://www.redalyc.org/articulo.oa?id=53427987003 Acesso em: 05 de jul. 2018.

AYOADE, J. O. Introdução à climatologia para os trópicos. Rio de Janeiro: Bertrand Brasil, 2003. 332p.

BARREIROS, D. L. P.; DUARTE, J. F. S.; IGAWA1, T. K.; SILVA, T. M.; ELLERES, F. A. P.; GUSMÃO, L. H. A. Estudo dos focos de calor no município de Parauapebas (PA) no período de 2005 a 2015. Anais do XVIII Simpósio Brasileiro de Sensoriamento Remoto - SBSR, Santos - SP, Brasil, 28 a 31 de maio de 2017, INPE. Disponível em: http://marte2.sid.inpe.br/col/sid.inpe.br/marte2/2017/10.27.13.55.43/doc/59853.pdf Acesso em: 02 de out. 2018.

COSTA, A. M. S.; BEZERRA, P. E. S.; DE OLIVEIRA, R. S. Mudanças no uso e ocupação da terra associadas a focos de calor na área de influência da Rodovia BR163 (Cuiabá-Santarém). Revista Brasileira de Gestão Ambiental, v. 11, n. 1, p. 119125, $2017 . \quad$ Disponível em: https://www.gvaa.com.br/revista/index.php/RBGA/article/viewFile/4956/4264 Acesso em: 20 de ago. 2018.

ENRÍQUEZ, M. A. R. S. Maldição ou dádiva? Os dilemas do desenvolvimento sustentável a partir de uma base mineira. 2007. $449 \mathrm{f}$. Tese (Doutorado em Desenvolvimento Sustentável) - Universidade de Brasília, Brasília, 2007. Disponível em: http://repositorio.unb.br/handle/10482/6417 Acesso em: 01 de jun. 2018.

FAPESPA - Fundação Amazônia de Amparo a Estudos e Pesquisas. Boletim informativo de pesquisas do Estado do Pará, 2016-2017. Disponível em: http://www.fapespa.pa.gov.br/ Acesso em: 20 de fev. 2018.

FEARNSIDE, Philip M. Fogo e emissão de gases de efeito estufa dos ecossistemas florestais da Amazônia brasileira. Estudos Avançados, v. 16, n. 44, p. 99-123, 2002. Disponível em: http://www.scielo.br/pdf/ea/v16n44/v16n44a07.pdf Acesso em: 01 de out. 2018. DOI: 10.1590/S0103-40142002000100007

FURTADO, Ana Maria Medeiros; DA PONTE, Franciney Carvalho. Ocupação e impactos decorrentes da expansão urbana da cidade de Parauapebas, estado do Pará. Revista do Instituto Histórico e Geográfico do Pará, v. 1, n. 01, 2014. 
Disponível em: http://www.ihgp.net.br/revista/index.php/revista/article/view/8 Acesso em: 02 de set. 2018.

GOMES, C. Geotecnologias da informação e remodelação do espaço urbano regional: Os sistemas de informação geográfica. Interface, v.3, n.3, p. 7-28, 2006. Disponível em:

https://sistemas.uft.edu.br/periodicos/index.php/interface/article/view/343 Acesso em: 15 de jul. 2018.

HECHT, S.B.; COCKBURN, A. The fate of the forest: developers, destroyers, and defenders of the Amazon. University of Chicago Press, Nova lorque, Verso, 1989. Disponível

em: http://journals.sagepub.com/doi/abs/10.1177/030981689004000114?journalCode=cnca Acesso em: 01 de jul. 2018. DOI: 10.1177/030981689004000114

HUBBeRT, K. R.; PREISleR, H. K.; WOHLGEMUth, P. M.; GRAHAM, R. C. \& NAROG, M. G. Prescribed burning effects on soil physical properties and soil water repellency in a steep chaparral watershed, southern California, USA. Geoderma, v. 130, n. 3-4, p. 284-298, 2006. Disponível em: https://www.sciencedirect.com/science/article/pii/S0016706105000443 Acesso em: 05 de ago. 2048. DOI: 10.1016/j.geoderma.2005.02.001

HUGHES, B. L.; SAUNDERS, M. A. A. Drought Climatology for Europe. International Journal of Climatology, v.22, p.1571-1592, 2002. Disponível em: https://rmets.onlinelibrary.wiley.com/doi/pdf/10.1002/joc.846 Acesso em: 22 de ago. 2018.

IBGE - Instituto Brasileiro de Geografia e Estatísticas, 2016. Estados. Disponível em: <http://www.ibge.gov.br/estadosat/perfil.php?sigla=pb>. Acesso em: 20 de fev. 2018.

IBGE - Instituto Brasileiro de Geografia e Estatísticas, 2018. Municípios. Disponível em: <https://cidades.ibge.gov.br/>. Acesso em: 20 de fev. 2018.

IBGE - Instituto Brasileiro de Geografia e Estatísticas, 2018. Sinopse do Senso Demográfico do Brasil - 2010. Disponível em: <https://cidades.ibge.gov.br/>. Acesso em: 26 de ago. 2018.

INMET - Instituto Nacional de Meteorologia. Dados meteorológicos - 2016. Disponível em: http://www.inmet.gov.br/portal/ Acesso em: 20 de fev. 2017.

INPE - Instituto Nacional de Pesquisas Espaciais, 2011. Monitoramento de Queimadas em Tempo Quase-Real do INPE. Perguntas frequentes. Disponível em $<$ http://sigma.cptec.inpe.br/queimadas/perguntas.html>. Acesso em: 20 de fev. 2018. 
INPE - Instituto Nacional de Pesquisas Espaciais, 2015. Portal do Monitoramento de Queimadas e Incêndios. Disponível em: <http://www.inpe.br/queimadas>. Acesso em: 20 de fev. 2018.

INPE - Instituto Nacional de Pesquisas Espaciais, 2017. Dados pontuais de focos de calor. Programa de Monitoramento de Focos. <http://sigma.cptec.inpe.br/queimadas/>. Acesso em: 20 de fev. 2018.

LAZZARINI, G. M. J.; FERREIRA, L. C. C.; FELICÍSSIMO, M. F. G.; OLIVEIRA, L. N.; ALVES, M. V. G. Análise da detecção e ocorrência de queimadas em áreas urbanizadas e entorno. Revista Ciência e Natura, Santa Maria v.38, n.3, 2016. Disponível em: https://periodicos.ufsm.br/cienciaenatura/article/view/21536 Acesso em: 01 de out. 2018.

LEONEL, M. O uso do fogo: o manejo indígena e a piromania da monocultura. Estudos Avançados, v. 14, n. 40, p. 231-250, 2000. Disponível em: http://www.scielo.br/pdf/ea/v14n40/v14n40a19.pdf Acesso em: 15 de ago. 2018.

LOPES, A. C. L.; FREITAS, A. V. M.; DA COSTA, D. O.; BELTRÃO, N. E. S.; \& TAVARES, P. A. Análise da distribuição de focos de calor no município de Novo Progresso-Pará. Revista Verde de Agroecologia e Desenvolvimento Sustentável, v. 12, n. 2, p. 298-303, 2017. Disponível em: https://www.gvaa.com.br/revista/index.php/RVADS/article/view/4843 Acesso em: 15 de ago. 2018.

MONTEIRO, M. A. Meio século de mineração industrial na Amazônia e suas implicações para o desenvolvimento regional. Estudos avançados, v. 19, n. 53, p. 187207, 2005. Disponível em: http://www.scielo.br/pdf/ea/v19n53/24088.pdf Acesso em: 22 de ago. 2018.

MORÁN, E. F. A ecologia humana das populações da Amazônia. Petrópolis, Vozes, 1990.

NOVAIS, J. W. Z.; SANTANNA, F. B.; ARRUDA, P. H. Z.; PEREIRA, O. A.; \& DUTRA, R. Relação entre profundidade óptica de aerossóis e radiação fotossinteticamente ativa e global no cerrado Mato-Grossense. Revista Estudo \& Debate, v. 24, n. 1, 2017. Disponível em: http://univates.br/revistas/index.php/estudoedebate/article/view/1180 Acesso em: 01 de set. 2018.

OLIVEIRA, U. C.; DE OLIVEIRA, P. S. Mapas de Kernel como Subsídio à Gestão Ambiental: Análise dos Focos de Calor na Bacia Hidrográfica do Rio Acaraú, Ceará, nos Anos 2010 a 2015. Espaço Aberto, v. 7, n. 1, p. 87-99, 2017. Disponível em: https://revistas.ufrj.br/index.php/EspacoAberto/article/viewFile/3473/8626 Acesso em: 01 de out. 2048. 
PEREIRA, J. A. V.; SILVA, J. B. Detecção de focos de calor no estado da Paraíba: um estudo sobre as queimadas. Revista Geografia Acadêmica, v.10, n.1, 2016. Disponível em: https://revista.ufrr.br/rga/article/view/3173 Acesso em: 01 de out. 2018

SETUR - Secretaria de Turismo de Pará-PA. Inventário da oferta turística de Parauapebas-PA. 2012. Disponível em:

http://www.setur.pa.gov.br/sites/default/files/pdf/inventario_parauapebas_0.pdf Acessado em: 15 de mar. 2018.

SILVA, R. R.; BACHA, C. J. C. Acessibilidade e aglomerações na Região Norte do Brasil sob o enfoque da Nova Geografia Econômica. Nova Economia, v. 24, n. 1, p. 169-190, 2014. Disponível em: http://www.scielo.br/pdf/neco/v24n1/0103-6351-neco-2401-0169.pdf Acesso em: 10 de set. 2018.

TOMZHINSKI, G. W. T.; COURA, P. H. F.; COUTO0, M. F. Avaliação da deteç̧ão de focos de calor por sensoriamento remoto para o Parque Nacional do Itatiaia. Biodiversidade Brasileira, 2011, 2: 201-2011. Disponível em: http://www.icmbio.gov.br/revistaeletronica/index.php/BioBR/article/view/140 Acesso em: 15 de set. 2018.

THOMAZ, E. L.; ANTONELI, V.; DOERR, S. H. Effects of fire on the physicochemical properties of soil in a slash-andburn agriculture. Catena, v. 122, p. 209-215, 2014. Disponível em: https://www.sciencedirect.com/science/article/pii/S0341816214001921 Acesso em: 18 de set. 2018. DOI: 10.1016/j.catena.2014.06.016

VIEIRA, J.; SOUZA, M.; TEIXEIRA, J.; CARVALHO, F. Estudo da precipitação mensal durante a estação chuvosa em Diamantina, Minas Gerais. Revista Brasileira de Engenharia Agrícola e Ambiental. Campina Grande, PB, v.14, n.7, p.762-767, 18 de fev. 2010. Disponível em: http://www.scielo.br/pdf/rbeaa/v14n7/a12v14n7.pdf Acesso em: 18 de set. 2018. 